\title{
Socioeconomic, Disease, and Biochemical Factors in Adherence to Anti Tuberculosis Treatment Regime in Benin City, Nigeria: A Comparative Study
}

\author{
A. O. Iyamu ${ }^{1}$, Onyeneke E. C ${ }^{2}$, J. E. Ugheoke ${ }^{3}$, W. A. Adisa ${ }^{4,}$, N. Akpede ${ }^{5}$, O. Aigbe ${ }^{1}$, G. Oko-Oboh ${ }^{6}$ \\ ${ }^{1}$ Department of Medical Biochemistry, College of medicine, Ambrose Alli University, Ekpoma, Nigeria \\ ${ }^{2}$ Department of biochemistry, University of Benin, Benin City, Nigeria \\ ${ }^{3}$ Department of Internal Medicine, Irrua Specialist Teaching Hospital, Irrua, Nigeria \\ ${ }^{4}$ Department of Human Physiology, College of Medicine, Ambrose Alli University, Ekpoma, Nigeria \\ ${ }^{5}$ Department of Community Health, Irrua Specialist Teaching Hospital, Irrua, Nigeria \\ ${ }^{6}$ Department of Community Health, University of Benin Teaching Hospital, Benin City, Nigeria \\ *Corresponding author: williamsadewumi@yahoo.com
}

Received February 28, 2013; Revised July 25, 2013; Accepted August 12, 2013

\begin{abstract}
Tuberculosis is a re-emergent disease of great epidemiological concern with the directly observed treatment short course (DOTS) recommended by the World Health Organization falling short of targeted expectations. The aim was to compare the impact of socioeconomic, disease, and biochemical factors on the decision of patients to return to (comply with) the six-month treatment schedule. Effects of education, age, occupational and marital (socioeconomic) and biochemical (drug side effects and values of biochemical indices of liver function) factors were compared between 52 SLR and 49 SNR patients. The results suggest that socioeconomic factors play a more prominent role than factors related to drug side effects in determining whether a patient returns to treatment after initial stoppage. A more integrated multi-disciplinary approach to DOTS administration with professional and social inputs is recommended
\end{abstract}

Keywords: adherence, tuberculosis, regime, socioeconomic, liver enzymes

Cite This Article: A. O. Iyamu, Onyeneke E. C, J. E. Ugheoke, W. A. Adisa, N. Akpede, O. Aigbe, and G.Oko-Oboh, "Socioeconomic, Disease, and Biochemical Factors in Adherence to Anti tuberculosis Treatment Regime in Benin City, Nigeria: A Comparative study.” American Journal of Biomedical Research 1, no. 4 (2013): 80-85. doi: 10.12691/ajbr-1-4-3.

\section{Introduction and Review of Literature}

Tuberculosis, according to the WHO, is an infectious bacterial disease, caused by Mycobacterium tuberculosis which commonly affects the lungs and is transmitted from person to person via droplets from the throat and nostrils of persons with the active respiratory disease [1]. A disease previously thought to have been globally put under control; tuberculosis has resurfaced as a major cause of morbidity and mortality worldwide primarily due to the global HIV/AIDS pandemics providing a platform for opportunistic infections. The disease remains an issue of great public health concern today despite the fact that effective treatment has been available for over fifty years [2]. The WHO found that the AR1 is highest in subSaharan Africa (1.5-2.5\%) and Asia (1.0-2.0\%). In Netherlands (a developed nation) the AR1 was estimated at $0.012 \%$ [4]. Without appropriate chemotherapy the death rate from tuberculosis is 50\% [5] and the estimated annual number of deaths from TB in developing countries is greater than 2.5 million or approximately $6.7 \%$ of all deaths[6].
The WHO global program on tuberculosis advocates for the use of directly observed treatment short course (DOTs) for all patients which involves giving Isoniazid, Rifampicin, Pyrazinamide and ethambutol for two months, then Isoniazid and Rifampicin alone for further four months and the patients is considered cured at six months $[3,5,7,8,9,10]$. It also advocates for home-based care of patients $[8,9,10]$. Biochemical side effects of drugs may be one factor that may affect compliance with drug treatment regime. Socioeconomic factors may also play a role [8]. In addition it is known that sufferers of a disease may or may not embrace a given management approach depending on the perception they have of their susceptibility to complications or the severity of symptoms [11] which in the case of tuberculosis include prolonged productive cough exceeding three months duration, chest pain, low grade intermittent fever, hemoptysis, night sweat, weight loss, appetite loss, easy fatigueability etc [12,13]. Awofeso and others [8] observed non-attendance and defaulting trends among community based TB patients in northern Nigeria and opined that the extent of treatment adherence (avoiding the use of the word compliance) may be facilitated by positive or negative attributes related to the healthcare 
system, social and family issues, personal and drug factors including medication side effects and drug formulation / combination. Other researchers have also studied the determinants of compliance or defaulting $[5,6]$.

All antituberculosis drugs, whether first, second or third lines are associated with undesirable side effects which may make their usage by patients somehow prohibitive $[8,9,10,12]$. The biggest problem with TB treatment is drug-induced hepatitis, which has a mortality rate of around 5\% [10]. Elevation in serum bilirubin levels must be expected with rifampicin treatment because the drug blocks bilirubin metabolism with compensatory excretion, and liver enzymes production increases accordingly. Elevation of liver transaminases such as serum glutamic oxaloacetate and glutamic pyruvic transaminases are common in the first three weeks of treatment [12]. Pyrazinamide is the drug most likely to cause painful arthralgia [10]. This study is designed to compare the role of socioeconomic and biochemical (disease / therapeutic) factors on the decision of patients to return to the DOTS facilities who had earlier absconded. It is a common tendency to ascribe the failure of many patients to complete the DOTS regimen to the side effects of antituberculous drugs. This study should help answer the question of whether there are other important factors that affect DOTS compliance.

\section{Methodology}

\subsection{Sample Population}

A total of 52 patients (29 males and 23 females) who had earlier stopped attending their DOTS facility for daily antituberculous therapy but later reappeared (SLR) and 49 patients (34 males and 15 females) who stopped but never returned (SNR) were used for this study. 10 private health facilities in Benin City, Nigeria which adopt the WHO DOTS recommendation were used for the study. Benin City is located in the south-south geopolitical zone of Nigeria. It is historically remarkable for its conservatism and cultural characteristics. Its population has witnessed explosive growth in the last two decades with influx of persons with culturally divergent background, leading to disruptive strain on the health, housing, and other infrastructural systems. Semi-slums are therefore noticeable in several parts of the City with the attendant increased risk of transmission of communicable diseases such as tuberculosis. The shift from cultural conservatism to socially liberalistic western lifestyle has led to increases in cases of HIV infection.

Blood samples were collected from the patients during follow up visits. All the samples were pooled and analyzed at a central laboratory.

Comparison was made (from hospital records) between the educational and socioeconomic status of the SLR and
SNR patients using; average age of patients, educational status, marital status, and occupational class. A similar comparison was made between the major complains and the mean values of liver function tests of the two groups as at the last follow-up visit.

\subsection{Case Definition}

Any patient with radiologic evidence of tuberculous pathology with any 5 of the following symptoms and predisposing factors including: prolonged ( $>3$ weekly duration) productive cough, chest pain, low grade intermittent fever, night sweats, appetite loss, weight loss, prior TB exposure, infection or disease, past TB treatment, and demographic risk factors for TB. Evidence of positive culture of mycobacterium tuberculosis was not considered necessary.

\subsection{Exclusion Criteria}

Any Patient who absconded but was brought back under unstable condition or out of own volition was excluded.

\subsection{Reagents}

All chemicals and reagents were analar grade and products of either BDH chemical limited (Poole, England) or Randox laboratories limited (USA).

\subsection{Blood Collection}

Blood samples were obtained from each patient in heparinized bottles and frozen in the refrigerator at $40^{\circ} \mathrm{C}$ before use. Liver function tests were done including total serum proteins, serum albumin, serum globulin, alkaline phosphatase, direct, indirect and total bilirubin, serum glutamic oxaloacetate transaminase (GOT, EC 2.6.1.1) and glutamic pyruvic transaminase (GPT, EC 2.6.1.2).

\section{Determination of Total Serum Proteins}

The method used was that of Biuret as described by Gornall et al [14]. The biuret procedure employs a colorimeter $\left(\mathrm{T}=25^{\circ} \mathrm{C}, \mathrm{A}_{540} \mathrm{~nm}\right.$, light path $\left.=1 \mathrm{~cm}\right)$ and is based on the reaction:

$$
\begin{aligned}
& \text { Copper }+ \text { Protein } \\
& \stackrel{\text { Alkaline } p H}{\longrightarrow} \text { Copper - protein complexes }
\end{aligned}
$$

The reagents used were $0.85 \%(\mathrm{w} / \mathrm{v}) \mathrm{NaCl} 0.5 \%(\mathrm{w} / \mathrm{v})$ Bovine serum albumin, Biuret reagent, patient sample solution (protein). The following volumes (mls) of reagents were put (pipette) into suitable containers as follows.

$\begin{array}{lccccccc} & \text { test } & \text { std 1 } & \text { std 2 } & \text { std 3 } & \text { std4 } & \text { std 5 } & \text { NaCl (blank) } \\ \mathrm{NaCl} & -- & 0.96 & 0.90 & 0.80 & 0.40 & -- & 1.00 \\ \text { Bovine serum Albumin } & -- & 0.04 & 0.10 & 0.20 & 0.60 & 1.00 & -- \\ \text { Patient sample (test protein) } & 1.00 & -- & -- & -- & -- & -- & -- \\ \text { (The contents of each container was mixed by swirling) } & & & & & & & \\ \text { Biuret reagent } & 4.00 & 4.00 & 4.00 & 4.00 & 4.00 & 4.00 & 4.00\end{array}$


The final content (after adding Biuret reagent) of each tube was mixed thoroughly by vortexing and then incubated for $30 \mathrm{mins}$ at $25^{\circ} \mathrm{C}$. The contents were then transferred to suitable cuvettes and absorbance read at 540nm for test, standards, and blank. The concentrations of the standards were used to plot a standard curve. The absorbance of the test solution was derived by subtracting the blank absorbance after extrapolating from the standard curve.

The concentration of total protein $\mathrm{mg}$ protein $/ \mathrm{ml}$ of test solution was calculated as

$$
M g \text { protein } / m l=\frac{m g \text { protein }}{m l \text { of patients sample }}
$$

\subsection{Quantitative Determination of Serum Albumin}

The method of Corcoran and Durnan [15] was adopted. Albumin is bound by the modified Bromocresol Green (BCG) dye to bring about an increase in the blue - green colour measured at $630 \mathrm{~nm}$. The colour increase is proportioned to the concentration of albumin present. The reagents used were Bromocresol Green 0.15 g/dl, Buffer, $\mathrm{pH} 4.66 \pm 0.1$, reactive ingredient, stabilizers, and surfactant all purchased as a ready-to-use single reagent. To each labeled tube (blank, standard, Test) was added $1.0 \mathrm{ml}$ of reagent. $0.01 \mathrm{ml}$ of sample was added to each tube and all the tubes were incubated at room temperate for one minute. The spectrophotometer was zeroed with the blank at $630 \mathrm{~nm}$. The absorbance were then read and recorded.

The concentration (g/dl) of albumin in test was calculated as:

$\frac{\text { Absorbance of test }}{\text { Absorbance of } s \tan \text { dard }} \times$ concentration of a tan dard (BSA)
Calculated from

$$
\begin{gathered}
U / m l=\frac{\Delta A / \min }{18.75} \times \frac{3.0}{0.10} \times 1000 \\
U / m l=\Delta A / \min \times 1000
\end{gathered}
$$

Where 18.75 = the absorbance of 1 umol/L p-nitrophenol in working buffer at $404 \mathrm{~nm}$ in a $1 \mathrm{~cm}$ path.

0.3 is the volume in the cuvette

0.1 is the sample volume

1000 is the factor converting to litre.

\subsection{Estimation of Serum Glutamic Oxaloacetate Transaminase (SGOT, EC 2.6.1.1)}

This was done using the colorimetric method of Reitman and Frankel [16]. SGOT catalyses the transformation of the substrate which contains $\alpha$ ketoglutarate and L-aspartate to yield L-glutamate and Oxaloacetate. The Oxalocetate formed reacts with 2,4, dinitrophenyl hydrazine to form Oxaloacetate hydrazone whose intensity is measured colorimetrically and is directly proportional to the activity of the aspartate aminotransferase in the reaction.

$$
\alpha \text {-Ketoglutate }+L \text {-asparate }
$$

$S G O D$

$\rightarrow$ L-glutamate + oxalocetate
The reagents were solution 1 (100m $\mathrm{M}$ phosphate buffer pH $7.4+$ L-aspartate + aketoghtarate, solution 2 (2, 4- dinitrophenyl hydrazine as concentration of $2 \mathrm{nM}$, and sodium hydroxide is $0.4 \mathrm{M}$, all stored at about $8^{0} \mathrm{C}$ in the refrigerator. Two test tubes were used; one for the blank and the other for the sample. $0.5 \mathrm{mls}$ of solution 1 was put in an empty test tube and in the tube containing $0.1 \mathrm{ml}$ of the patient's serum and incubated for $30 \mathrm{~min}$ at $37^{\circ} \mathrm{c}$. $0.5 \mathrm{ml}$ of 2,4 dinitrophenyl hydrazine was added to each tube and the content of each tube was mixed and allowed to stand for $20 \mathrm{~min}$ at $25^{\circ} \mathrm{C}$. Finally $5 \mathrm{ml}$ of Sodium hydroxide was added to each test tube. After mixing, the absorbance of the sample was read against the blank after 5 minutes at $546 \mathrm{~nm}$. The corresponding SGOT value was deduced from the available SGOT value - absorbance chart in iu/L.

\subsection{Determination of Serum Glutamic Pyruvic Transaminase (SGPT, 2.6.1.2)}

The same method of Reitman and Frankel [16] was adopted. This enzyme catalyzes the transformation of the substrate to yield L-glutamate and pyruvate. The pyruvate formed reacts with the 2,4-dinitrophenyl hydrazine to form pyruvichydrazone, a coloured complex, whose intensity is measured colorimetrically and is proportional to the activity of the alanine aminotransaminase. Phosphate buffer, L-alanine, and $\alpha$-ketoglutarate made up the solution in this case.

\subsection{Determination of Direct, Indirect and Total Bilirubin}

This was done by the colorimetric method of Vanden Bergh as discussed by Lathe and Ruthven [17]. Two forms of bilirubin exist in plasma, both of which are bound to albumin. These are non-esterified or unconjugated bilirubin, and bilirubin diglucuronide (conjugated bilirubin). The concentration of the unconjugated faction is obtained by subtracting the conjugated form from the total bilirubin.Bilirubin can be converted into an azodyewhich absorbance at specific wavelength can be measured. Both conjugated and unjugated forms are split at the middle by the diazo reaction to form two dipyroles with loss of the methylene bridge at the scission point. Each dipyrrole forms an azo dye by coupling with the diazonium salt, with the resulting azobilirubins having essentially the same spectral absorbance value.

The reagents included $0.20 \mathrm{M} \mathrm{HCl}$. Diazoreactant prepared from sulfanilic acid (0.058M) and 0.072M $\mathrm{NaNO}_{2}$ bilirubin standard solution (standard bilirubin + directly sulfoxide + Bovine serum albumin)

To determine the conjugated bilirubin test and blank tubes were set for each specimen and standard containing $0.75 \mathrm{ml}$ of water and 50ul unknown serum. The same was done for control serum and standard $0.2 \mathrm{ml}$ of diazo reagent was added to all tubes marked "test" and $0.2 \mathrm{u}$ Sulfanilic acid to all tubes marked "blanked". The tubes were allowed to stand for 5 minutes and then read in sequence against a water blank at 50nm.

For the determination of total bilirubin $1.0 \mathrm{ml}$ methanol was added to all the tubes above, both test and blank, mixed well, and allowed to stand for 30 minutes at room temperature, and then read at 560nm. 
Total bilirubin (mg/dl) was calculated as

$$
=\frac{\Delta A u}{A s} \times C
$$

Esterified bilirubin (mg/dl) was also calculated using the same equation but methanol was not added before the absorbance were read.

$\Delta A u=$ difference in absorbance between unknown and blank.

As $=$ the absorbance of the standard read at 5 minutes.

$\mathrm{C}=$ the bilirubin concentration of the Bovine serum (standard).

\subsection{Statistical Analysis}

The statistical program for the social sciences (SPSS) version 17.0 was used to determine the means of various indices of liver function tests for the SLR and SNR groups.

\section{Results}

The results of the sociodemographic and economic parameters of patients complains, and liver function indices compared between the SLR and SNR groups of patients is presented in Table 1, Table 2, Table 3, Table 4, Table 5, and Table 6.

Table 1. Comparison of educational status of SLR and SNR patients

\begin{tabular}{|l|c|c|}
\hline Highest level of Education & SLR (\%) & SNR (\%) \\
\hline * No Contact with Education & 7.69 & 24.44 \\
* Primary School & 17.30 & 2.04 \\
* Secondary School & 59.61 & 8.16 \\
* Tertiary Education & 13.46 & 65.31 \\
\hline
\end{tabular}

Table 2. Comparison of mean age between SLR and SNR patients

\begin{tabular}{|c|c|c|}
\hline & SLR & SNR \\
\hline Meanage \pm SD (yrs) & $38.23 \pm 12.46$ & $52.16 \pm 31$ \\
\hline
\end{tabular}

Table 3. Comparison of marital status between SLR and SNR patients

\begin{tabular}{|l|c|c|}
\hline Marital status & SLR(\%) & SNR(\%) \\
\hline * Married & 71.15 & 18.52 \\
* Unmarried & 17.31 & 05.97 \\
* Divorced & 07.69 & 34.69 \\
* Separated & 03.85 & 40.82 \\
\hline
\end{tabular}

Table 4. Comparison of occupational affiliation (classified according to the ILO [18]) of SLR and SNR patients

\begin{tabular}{|c|c|c|}
\hline OCCUPATIONAL AFFILIATION $\{20\}$ & SLR(No of patients) & SNR(No of patients) \\
\hline * Managers & Nil & 14 \\
\hline * Professional Occupations & 1 & 10 \\
\hline * Technicians and Associate Professionals & 2 & 2 \\
\hline * Clerical Support workers & 3 & 2 \\
\hline * Service and Sales workers & 23 & 6 \\
\hline * Skilled Agricultural, Forestry and Fishery workers & 8 & 3 \\
\hline * Craft and related trade workers & 11 & 7 \\
\hline * Plant and Machine operators and assemblers & 4 & 5 \\
\hline * Armed forces occupations & Nil & Nil \\
\hline
\end{tabular}

Table 5. Comparison of the major complains between SLR and SNR patients as at the last visit before stoppage of treatment

\begin{tabular}{|l|c|}
\hline Complain as at the last review before stoppage of treatment (Number of patients) & SLR (No of patients) \\
\hline * Frightening coloration of urine & 15 \\
$*$ Yellowness of the eyes & 8 \\
$*$ Unbearable itching & 21 \\
$*$ Blurred vision or eye pain & -- \\
$*$ painful joints & 24 \\
$*$ Unfriendly o disrespectful attitude of facility staff & -- \\
\hline
\end{tabular}

Table 6. Comparison of the mean values of the liver function indices between the SLR and SNR patients

\begin{tabular}{|c|c|c|c|}
\hline Values of liver function indices as at the last liver function test & SLR & SNR & $P$ value \\
\hline * Serum total protein(TB, g/dl) & $5.741 \pm 0.434$ & $5.726 \pm 0.396$ & $\mathrm{P}>0.05$ \\
\hline * Serum albumin (Alb,g/dl) & $4.125 \pm 0.625$ & $4.127 \pm 0.411$ & $\mathrm{P}>0.05$ \\
\hline * Serum globulin (Glob, g/dl) & $1.544 \pm 0.526$ & $1.567 \pm 0.296$ & $\mathrm{P}>0.05$ \\
\hline * Alkaline phosphatase (iu/dl) & $171.012 \pm 0.196$ & $154.874 \pm 0.634$ & $\mathrm{P}<0.05$ \\
\hline * Serum glutamate oxaloacetate aminotransferase (ku) & $25.245 \pm 0.644$ & $24.628 \pm 0.467$ & $\mathrm{P}>0.05$ \\
\hline * Serum glutamic pyruvic aminotransferase (ku) & $30.169 \pm 0.736$ & $28.425 \pm 0.339$ & $\mathrm{P}>0.05$ \\
\hline * Direct Bilirubin (g/dl) & $0.439 \pm 0.025$ & $0.431 \pm 0.397$ & $\mathrm{P}>0.05$ \\
\hline * Indirect Bilirubin (g/dl) & $0.381 \pm 0.023$ & $0.384 \pm 0.022$ & $\mathrm{P}>0.05$ \\
\hline * Total Bilirubin (g/dl) & $0.812 \pm 0.109$ & $0.799 \pm 0.147$ & $\mathrm{P}>0.05$ \\
\hline
\end{tabular}




\section{Discussion}

Tuberculosis remains an important public health issue especially in developing countries where the predisposing factors are commonly found. Poor housing, inadequate nutrition as a result of poverty are some important factors. A comparison of educational status between the SLR and SNR groups (Table 1) shows that at the extremes of the scale of educational status (no contact with education and tertiary education) were found those who absconded and never returned. It may be easily understood why those with absolute illiteracy may never return after absconded. The reason why those who are very well educated (tertiary education) did not return to treatment may however be difficult to decipher. However their presumably better socioeconomic status may suggest that they are able to afford treatment at more organized and sophisticated centers which may be more expensive than the private facilities where this study was conducted and so they can afford better ones when they get dissatisfied with a DOT facility. Some may even opt for home based care.

Age was also found to be a factor (Table 2). Older persons were found to be less likely to return after stoppage. The reason for this is not so clear but the perceived threat of tuberculosis, which Rosenstock [11] identified as a major factor in the decision whether to embrace a health programme or not, is more likely to be exaggerated by the young, who may also tolerate imperfections because of their lower self esteem, than the older ones. The older ones may also have a higher propensity to endure the symptoms of the disease and drug side effects instead of running back to the facility.

Marital status was found to be a determinant of whether a patient will return or not. From Table 3 it can be seen that those who are separated or divorced are less likely to return to treatment. Stable marriage comes with more social responsibility and accountability. Most marriage persons not only think of their welfare but also that of their spouses and children. This thought of the welfare of their dependants may make them return to treatment to avoid plunging these dependants into suffering which may be the case if they (the patients) die. The comparison between occupational affiliation of SLR and SNR patients is also remarkable (Table 4). There were more SNR than SLR patients up the ladder according to the ILO classification of occupational status [18]. Most of those who stopped and later returned were in the middle class while a higher percentage of those who stopped and never returned where in the upper class than in the middle and lower classes. This is closely related to the effect of education and further emphasizes the importance of education to health- seeking behavior. High educational rating also translates to high economic rating which is a major factor in the making of health related decisions.

Complaints related to side effects (Table 5) and the indices of liver function test (Table 6) are related to the biochemical processes involved in both the natural history and chemotherapy. From these tables it can be seen that there are no sharp differences between the two groups. Apart from the difference in complains about the unfriendly or disrespectful attitude of facility staff which is actually a social issue. In this regard it was seen that far more SNR patients than SLR patients indicating that social issues are very important determinants of healthseeking behaviors.

The current study is in support of Awofeso at el [8] who had earlier stated that social and family issues may facilitate the extent of TB treatment adherence. It also betrays the common attribution of stoppage of DOTS regime to the effect of drug side effects.

\section{Conclusion and Recommendation}

Tuberculosis has been unearthed by the ravaging claws of HIV/AIDS. The menace of TB is especially worrisome in many developing countries were housing conditions are poor and government budgetary commitment to health are laughably pretentious. It can be seen from the present study that while there were clear differences between the average age, educational status, occupational affiliation, marital status, and complain about attitude of facility staff (socioeconomic factors) between the SLR and SNR patients, there were no clear differences between complains of drug side effects and biochemical indices of liver function. This suggests that socioeconomic factors play a more important role in determining whether a patient returns to treatment or not after stopping and hence are more important determinant of patient adherence to the DOTS regime or not. A multidisciplinary approach to the DOTS strategy is therefore recommended with emphasis on a clearly defined role for the social scientist. We also recommend that private, and not only public health facilities, be well integrated into the DOTS scheme since these are usually closer to the local communities and many patients shy away from government -run health facilities. The overall purpose is to ensure that we scale up to meet targets in global tuberculosis control $[19,20,21,22,23]$.

$\begin{array}{ll}\text { Abbreviations } \\ \text { DOTS } & \begin{array}{l}\text { Directly observed treatment short course } \\ \text { SLR }\end{array} \\ \text { SNR } & \text { Stopped treatment but later returned } \\ \text { HIV/AIDs } & \begin{array}{l}\text { Human immunodeficiency virus, } \\ \text { acquired. Immunodeficiency }\end{array} \\ \text { WHO } & \text { World Health organization } \\ \text { AR1 } & \text { The probability that any person will be } \\ & \text { infected with mycobacterium. } \\ \text { TB } & \text { Tuberculosis in 1 year } \\ \text { BCG } & \text { tuberculosis } \\ \text { ILO } & \text { Bromocresol Green } \\ & \text { International labour organization. }\end{array}$

\section{References}

[1] Global Tuberculosis Report WHO (2012).

[2] Dohn PJ, Raviglone MC, Koch; A Global Tuberculosis Incidence And Mortality During 1999-2000. Bull world health organ, 72(2): 212-220. 1994.

[3] Maher D, Hauster HP, Ravighone MC. Tuberculosis Care In Community Care Organizations In Sub-Sahara Africa: Practice and Potential. International Journal of Tuberculosis Lung Disease,1(3): 276-283. 1997. 
[4] Kironde S, Tuberculosis. In: Ntuli A, Crisp N, Clarke E, Baron P, Editors, South African Health Review 2000. Durban: Health Systems Trust pp 335-349.

[5] Teckle B, Mariam DH, and Ali A. Defaulting from DOTS and its determinant in three districts of Arizona in EthopiaInterational Journal of Tuberculosis Lung Disease, 6:574-579. 2002.

[6] Fox W. Compliance of Patients and Physicians. Experience and Lessons from Tuberculosis. BAAJ, 287:33-37.1983.

[7] Burke and Parnell. Minimal Pulmonary Tuberculosis; Canadian Medical Association Journal, 59:348. 1948.

[8] Awofeso N. Antituberculosis medication side effects constitute a major factor for poor adherence for tuberculosis treatment. Bull World Health Organization (2008).

[9] William BG. What is the limit of case detection under the DOTS strategy for tuberculosis control? Tuberculosis, 83 (1-3):35-43. 2003.

[10] Forget EJ, and Menzes D. Adverse reaction to first line antituberculosis drugs. Expert Opinion on Drug Safety, 5(2)231249. 2006.

[11] Rosenstock IM. Why People Use Health Services. Millbank Memorial Fund Quarterly, 44(3): 94-127. 1966.

[12] Schaberg T, Rebham KM, and Lode H. Risk factors for side effects of isonazids, rifampicine, pyrazinamide, in patients hospitalized for pulmonary tuberculosis. European Respect Journal, 9: 2026-2030. 1996.

[13] Kumar V, Abbas AK, Fausto W and Mitchell RM. Robbins Basic Pathology. (8th Ed.) Saundsers Elsevier,Pp 516-522. 2007.
[14] Gornall AG, Bardawill CJ and David MM. Determination of Serum Proteins by means of the Biuret Reaction. Journal of Biological Chemistry, 177:751. 1949.

[15] Corcaran RM and Durnan SM: Albumin determination by a modified bronicresol green method. Clinical Chemistry, 23(4):765-766. 1977.

[16] Reitman S, Frankel S. A Calorimetric method for the determination of serum glutamic oxaloacetate and glutamic pyruvic transaminases. American Journal of Clinical Pathology, 28:53-56. 1988

[17] Lathe, GH and Ruthven LRT. Factors affecting the rate of coupling of bilirubin and conjugated bilrubin in the Van den Bergh reaction. J Clin pathol 71:155,1958

[18] International Labour Organization. International Standard Classification of Occupation (2011).

[19] Garner P, Smith H, Munro S, Volmink J. Promoting adherence to tuberculosis treatment. Bull World Health Organ, 85:404-6. 2007.

[20] Conrad P. The meaning of medication: another look at compliance. Soc Sci Med., 20: 29-37. 1985.

[21] Building on and enhancing DOTS to meet the TB-related Millennium Development Goals. Geneva: WHO: 2006. http://www.who.int/tb/ publications /2006/ who htmtb 2006386.

[22] Self - Study Modules on tuberculosis: Patient adherence to tuberculosis treatment Washington DC: National Centre for HIV, STD and TB Prevention, US Department of Health and Human Services; 1999. http://www.cdc.ov/tb/pubs/ssmodules/pdfs/9.pdf.

[23] Elzinga G, Rarighone MC, Maher D. "Scale up: Meeting targets in global tuberculosis control”. Lancet, 63 (9411): 814-19. 2004. 